\title{
A case study of feline triaditis
}

\author{
Fadhilah A. Haq ${ }^{1}$, Afifah Hasna ${ }^{1}$, Damar P. Kusumarini ${ }^{1}$, Arief P. Mihardi ${ }^{2,3^{*}}$, Malni Sovinar ${ }^{3}$ \\ ${ }^{1}$ Student of Veterinary Professional Education Program, Faculty of Veterinary Medicine, IPB University, Bogor \\ ${ }^{2}$ Department of Clinic, Reproduction, and Pathology, Faculty of Veterinary Medicine, IPB University, Bogor \\ ${ }^{3}$ Veterinary Practitioner, Bobon and Vet, Bogor
}

\begin{abstract}
Triaditis is an inflammatory condition involving three specific organs, namely the pancreas, liver, and intestines. The most common clinical signs of triaditis are vomiting, diarrhea, jaundice, and loss of appetite. Therefore, this case study was con-ducted to determine cases of triaditis in cats with these clinical signs. This case study was carried out on five cats with diarrhea, lethargy, and loss of appetite. The fecal scores of cats with diarrhea were 2 and 3 . Based on physical examination, there were two cats with hepatomegaly and three cats with jaundice on their mucosa. Treatments for five cats with diarrhea were antibiotic combination (sulfadiazine-trimetropine $50 \mathrm{mg} / \mathrm{kg} \mathrm{BW}$ ) and combination of antispasmodic, analgesic, and antipyret-ic (dipyrone-lidocaine $5 \mathrm{mg} / \mathrm{kg} \mathrm{BW}$ ). Treatments for three cats with jaundice were asering fluid therapy and oral medication (ursodeoxycholic acid $8 \mathrm{mg} / \mathrm{kg} \mathrm{BW}$ ). Anthelmintic combination (fenbendazole, praziquantel, and pyrantel pamoate $0.07 \mathrm{~g} / \mathrm{kg}$ BW) was given as an additional therapy for cats with intestinal worms. The two cats with diarrhea, hepatomegaly and jaundice were not survive after about one week of treatment, while the other one can survive until now.
\end{abstract}

Keywords:

diarrhea, feline, jaundice, triaditis

\section{- INTRODUCTION}

Cat (Felis catus) has unique anatomy of the hepatic-pancreatic-intestinal region. The bile duct and pancreatic duct are open into the duodenum of small intestine through only one opening. In fact, feline duodenum also reportedly contains 100 times more bacteria than in the canine duodenum. Thus, vomiting caused by a single organ abnormality may give rise to a reflux of the bacteria-rich duodenum juice into the liver and pancreas (Ishida 2011). This unique and interrelated anatomy of the pancreas, small intestine, and the biliary system is thought to predispose to the development of inflammation in those three systems (Mansfield 2014). When the inflammatory disease of those three specific organs in a cat happen concurrently, the condition is called feline triaditis.

Triaditis has been reported in 50 to $56 \%$ of cats diagnosed with pancreatitis and $32-50 \%$ of those with cholangitis/inflammatory liver disease (Simpson 2015). Pancreatitis, cholangiohepatitis, and IBD manifest with overlapping, vague and non-specific clinical signs. The most common clinical signs of pancreatitis in cat are loss of appetite, lethargy, vomiting, jaundice, dehydration, abdominal pain, and weight loss (Cridge \& Sullivant 2018). Therefore, definitive diagnosis of triaditis can only be confirmed with histopathology and it remains a presumptive diagnosis in most cases (Černá et al. 2020). The aim of this study was to determine triaditis in five cats with clinical signs such as diarrhea, lethargy, and loss of appetite.

\section{- MATERIALS AND METHOD}

This study involved five domestic cats admitted to Home Pet Clinic Bekasi in September 2020. Five cats came to the clinic with diarrhea, lethargy, and loss of appetite. When observed, the fecal scores of the five cats were 2 and 3 out of 5 . Physical examination was carried out to see other clinical findings and supporting data obtained from previous stool evaluation.

\section{- RESULT AND DISCUSSION}

The results of physical examination on five cats in this study was the presence of jaundice on three cats with medical record numbers 40-20, 41-20, and 44-20 (Table 1). The liver was enlarged in two cats with the medical record numbers 41-20 and 44-20, when the abdominal area was palpated. Refers to Simpson (2015), jaundice and hepatomegaly are symptoms that can be used to establish a diagnosis of triaditis originating from inflammatory liver disease.

\begin{tabular}{|ccccccc|}
\multicolumn{7}{c}{ Table 1 Clinical signs and stool results from five cats } \\
\begin{tabular}{|ccccccc}
\hline Medical & \multicolumn{5}{c}{ Clinical Signs } & \multicolumn{3}{c|}{ Stool Results } \\
\cline { 2 - 6 } Record & Diarrhea Jaundice Hepatomegaly & Steatorrhea Helminthiasis \\
\hline $30-20$ & + & - & - & - & - \\
$39-20$ & + & - & - & - & + \\
$40-20$ & + & + & - & + & + \\
$41-20$ & + & + & + & + & + \\
$44-20$ & + & + & + & - & + \\
\hline
\end{tabular}
\end{tabular}

Received: 11-08-2021 | Revised: 01-09-2021 | Accepted: 03-09-2021 (C) 2021 CC-BY-SA. This is an Open Access article that is distributed under the terms of Creative Commons Attribution ShareAlike 4.0 International License (https://creativecommons.org/licenses/by-sa/4.0/). 
The previous stool analysis, four cats with medical record numbers 39-20, 40-20, 41-20, and 44-20 were diagnosed helminthiasis. The presence of hooked worms in the intestine could injure the intestinal mucosa. Intestinal inflammation could be the primary stimulus of enteric bacteria translocation to the pancreas and liver. An increase in intra-duodenal pressure during vomiting could also promote reflux of enteric contents into the pancreatico-biliary duct leading to concurrent inflammation, bacterial infection of the liver and pancreas (Twedt et al. 2014). Stool analysis showed the presence of undigested fat (steatorrhea) in two cats with medical record numbers 40-20 and 41-20. The presence of undigested fat in feces indicates fat digestion disorder in the pancreas. That could lead to the development of triaditis through its impact on the intestines and liver (Janeczko et al. 2008; Steiner 2014).

Five cats in this study has diarrhea symptom and two of them with medical record numbers 41-20 and 44-20 were diagnosed positive for triaditis and got antibiotics therapy with combination of sulfadiazine-trimetropine $50 \mathrm{mg} / \mathrm{kg}$ $\mathrm{BW}$. This combination is able to penetrate into the exudate of infected tissue (Plumb 2008). According to Černá et al. (2020) the alternative antibiotic is amoxicillin clavulanate with $10-20 \mathrm{mg} / \mathrm{kg} \mathrm{BW}$ dose in SC/PO route for 2-3 times a day. Meanwhile the administration of metronidazole in this case is not very recommended because it is partially metabolized in the liver and kidneys, then excreted through urine and feces.

The first treatment using parenteral crystalloid fluid can be used in cats with triaditis. Fluid therapy is intended to improve dehydration that occurs during the previous 12-24 hours and replace fluid loss because of vomiting, diarrhea, and fluid loss in peritoneal effusion due to alkaline acid imbalance (Černá et al. 2020). Combination of antispasmodic, analgesic, and antipyretic (dipyronelidocaine $5 \mathrm{mg} / \mathrm{kg} \mathrm{BW}$ ) can be used in cat with triaditis to overcome diarrhea. Analgesic administration is aimed to reduce abdominal pain due to multiorgan abnormalities, reduce the risk of fluid deficiency, anorexia, and nausea (Rusbridge et al. 2010). According to Černá et al. (2020) antiemetic can also be used to reduce the effects of vomiting and reduce visceral pain although the incidence of vomiting in triaditis patients is rare but this treatment is useful.

Additional therapy to four cats with helminthiasis is anthelmintic with combination of fenbendazole, praziquantel, and pyrantel pamoate $0.07 \mathrm{~g} / \mathrm{kg}$ BW. Anthelmintic administration is intended to reduce infection due to parasites in the intestines which encourage the occurrence of triaditis developed from IBD (Arion et al. 2018). Other therapy for feline triaditis is ursodeoxycholic (UDCA) to reduce jaundice symptom. UDCA can convert saturated bile into unsaturated bile, and the instauration increases the transport capacity of bile for cholesterol. Clinically, long-term UDCA therapy improves liver function tests and prohibit the development of cirrhosis (El Sherbiny et al. 2009).

\section{- CONCLUSION}

Based on the clinical symptoms of five cats, two of them were suspected of having triaditis with symptoms of diarrhea, jaundice, and hepatomegaly. Further examination also showed the presence of steatorrhea and helminthiasis in the two cats that were suspected of having triaditis. The therapy given is symptomatic with fluid therapy, antibiotic, antispasmodic, analgesic, antipyretic, and anthelmintic.

\section{aUTHOR INFORMATION}

\section{Corresponding Author}

*APM: mihardi.ap@apps.ipb.ac.id

Divisi Penyakit Dalam, Wing 2, Level 3. Departemen Klinik, Reproduksi dan Patologi, Fakultas Kedokteran Hewan, IPB University, Jl. Agatis, Kampus IPB Dramaga Bogor 16680 INDONESIA

\section{- REFERENCES}

Arion A, Fernandez-Varon E, Carceles CM, Gagyi L, dan Ognean L. 2018. Pharmacokinetics of praziquantel and pyrantel pamoate combination following oral administration in cats. Journal of Feline Medicine and Surgery. 20(10):900-904.

Černá P, Kilpatrick S, Gunn-Moore DA. 2020. Feline comorbidities: what do we really know about feline triaditis? Journal of Feline Medicine and Surgery. 22(11): 1047-1067

Cridge H, Sullivant A. 2018. Canine and feline pancreatitis. Veterinary Ireland Journal. 8(6):367-372.

El Sherbiny GA, Taye A, Raheem ITA. 2009. Role of ursodeoxycholic acid in prevention of hepatotoxicity caused by amoxicillin-clavulanic acid in rats. Annals of Hepatology. 8(2):134-140.

Ishida T. 2011. Feline triaditis: inflammatory diseases of the liver, pancreas and small intestine. World Small Animal Veterinary Association Congress; 2011; Jeju, Korea. Jeju (KR): World Small Animal Veterinary Association World Congress Proceedings.

Janeczko S, Atwater D, Bogel, E. 2008. The relationship of mucosal bacteria to duodenal histopathology, cytokine mRNA, and clinical disease activity in cats with inflammatory bowel disease. Veterinary Microbiology. 128(1-2):178-193.

Mansfield C. 2014. Triaditis in cats - does it exist. World Small Animal Veterinary Association Congress; 16-19 September 2014; Cape Town, South Africa. Cape Town (ZA): World Small Animal Veterinary Association World Congress Proceedings.

Plumb DC. 2008. Plumb's Veterinary Drug Handbook Sixth Edition. Wisconsin (US): PharmaVet Inc.

Rusbridge C, Heath S, Gunn-Moore DA, Knowler SP, Johnston N, McFadyen AK. 2010. Feline orofacial pain syndrome (FOPS): a retrospective study of 113 cases. Journal of Feline Medicine and Surgery. 12(6):498-508.

Simpson KW. 2015. Pancreatitis and triaditis in cats: causes and treatment. Journal of Small Animal Practice. 56(1):40-49.

Steiner JM. 2014. Exocrine Pancreatic Insufficiency in Cats. World Small Animal Veterinary Association Congress; 16-19 September 2014; Cape Town, South Africa. Cape Town (ZA): World Small Animal Veterinary Association Congress Proceedings: 1-5

Twedt DC, Cullen J, McCord K. 2014. Evaluation of fluorescence in situ hybridization for the detection of bacteria in feline inflammatory liver disease. Journal of Small Animal Practice 16(2):109-117. 